\title{
Capsule Commentary on Alagoz et al., Benefits and Harms of Mammography Screening for Women with Down Syndrome
}

\author{
Peter Bulova, MD \\ General Internal Medicine, The University of Pittsburgh Medical Center, Pittsburgh, PA, USA.
}

J Gen Intern Med 34(11):2581

DOI: $10.1007 / \mathrm{s} 11606-019-05295-\mathrm{x}$

(c) Society of General Internal Medicine 2019

$\mathrm{L}$ ife expectancy for women with Down syndrome is approximately 57.5 years. ${ }^{1}$ This is due to the high risk of dementia, which has been shown to be involved in $70 \%$ of deaths of adults with Down syndrome over 35 years old. ${ }^{2}$ The risk of solid tumors is also much lower than in people without Down syndrome, ${ }^{3}$ with rates of breast cancer conservatively estimated to be $25 \%$ of those without Down syndrome. ${ }^{4}$ These facts make our current screening guidelines for breast cancer seem inappropriate and likely harmful for adults with Down syndrome. However, there are no modifications to USPSTF guidelines in screening for adults with Down syndrome, as there are no large randomized controlled studies to inform practice.

In lieu of a large randomized control trial, Alagoz et al. ${ }^{4}$ perform a computer simulation modeling of the efficacy of mammograms in adults with Down syndrome. They compare life years gained with the harm of false positives in a population with limited life expectancy and lower risk of cancer. Their resulting benefit ratio makes our current guidelines inappropriate for this population.

This information is practice changing. It can augment the conversation with patients, their caregivers, and their providers regarding mammograms in a group that can find them traumatic. In addition, this is a model for use on other specific populations where large randomized controlled trials are not feasible. One could see this method being used in other conditions in which life expectancy is limited, or when cancer rates are different than the average for the general population. An example that seems appropriate for the same model is the screening for colon cancer in adults with Down syndrome, as the risk of death from all solid tumors is dramatically lower compared with that of the general population. ${ }^{3}$

One caveat is that we must keep in mind other benefits to screening such as normalization of an underserved population. At this point, women with intellectual disabilities receive lower rates of screening compared with the general population. ${ }^{5}$ One must be careful not to state that this population is less deserving of screening. However, the data in this article is very convincing that we are over-screening for breast cancer, and guidelines should reflect this.

Corresponding Author: Peter Bulova, MD; General Internal Medicine The University of Pittsburgh Medical Center, Pittsburgh, PA, USA (e-mail: bulovapd@upmc.edu).

\section{Compliance with Ethical Standards:}

Conflict of Interest: The author declares that he does not have a conflict of interest.

\section{REFERENCES}

1. Day SM, Strauss DJ, Shavelle RM, Reynolds RJ. Mortality and causes of death in persons with Down syndrome in California. Dev Med Child Neurol. 2005;47(3):171-6.

2. Hithersay R, Startin CM, Hamburg $\mathbf{S}$, et al. Association of dementia with mortality among adults with Down syndrome older than 35 years [published online November 19, 2018]. JAMA Neurol.

3. Hasle H, Friedman JM, Olsen JH, Rasmussen SA. Low risk of solid tumors in persons with Down syndrome. Genet Med. 2016;18:1151-1157.

4. Alagoz O, Hajjar A, Chootipongchaivat S, van Ravesteyn NT, Yeh J, Ergun MA, de Koning HJ, Chicoine B, Martin B. Benefits and Harms of Mammography Screening for Women with Down Syndrome: A Collaborative Modeling Study. J Gen Intern Med. https://doi.org/10.1007/s11606019-05182-5.

5. Cobigo V, Ouellette-Kuntz H, Balogh R, Leung F, Lin E, Lunsky Y. Are cervical and breast cancer screening programmes equitable? The case of women with intellectual and developmental disabilities. J Intell Disabil Res2013;57( 5), 478-488.

Publisher's Note Springer Nature remains neutral with regard to jurisdictional claims in published maps and institutional affiliations. 